\title{
O PLANTIO DE ÁGUA NA PERSPECTIVA DA TRANSIÇÃO AGROECOLÓGICA: O CASO DO SÍTIO PEDRA BRILHANTE
}

\author{
Nágila Scarpi Nespoli ${ }^{1}$ \\ Leonard Campos Avellar Machado² \\ Haloysio Miguel de Siqueira ${ }^{3}$
}

Resumo: Os agricultores que se enquadram como familiares, podem recuperar suas APP's de curso d'água tendo como base princípios da agroecologia. No Sítio Pedra Brilhante estão sendo desenvolvidos trabalhos de "plantio de água", trata-se da combinação de tecnologias sociais, de baixo custo, que podem ser utilizadas por agricultores familiares para evitar a degradação de nascentes e cursos d'água. Com o trabalho objetivou-se realizar o monitoramento participativo de uma adequação ambiental, tendo em vista o processo de transição agroecológica. As metodologias utilizadas foram: monitoramento participativo e levantamento de práticas agroecológicas. Este estudo mostrou que é possível iniciar a transição agroecológica trabalhando, desde o começo, com estratégias que correspondem aos três estádios da transição.

Palavras-chaves: Caixas secas; Monitoramento participativo; Agricultura familiar, Recursos hídricos; Técnicas conservacionistas.

\footnotetext{
${ }^{1}$ Zootecnia/Universidade Federal do Espírito Santo, Brasil. E-mail: nagila.sn@gmail.com.

2 Engenheiro Agrônomo/Grupo de Agricultura Ecológica Kapi'xawa, Brasil. E-mail: leonardcamachado@gmail.com.

3 Departamento de Medicina Veterinária /Universidade Federal do Espírito Santo, Brasil. E-mail: haloysio.siqueira@ufes.br.
} 